\title{
Refusal Strategy Used by Malay and German Native Speakers to Refuse Requests
}

\author{
Farhana Muslim Mohd Jalis ${ }^{1}$, Mohd Azidan Abdul Jabarr ${ }^{1}$, Hazlina Abdul Halim ${ }^{1} \&$ Jürgen Martin Bukhardt ${ }^{1}$ \\ ${ }^{1}$ Department of Foreign Languages, Faculty of Modern Languages and Communication, Universiti Putra \\ Malaysia, UPM Serdang, Selangor, Malaysia \\ Correspondence: Farhana Muslim Mohd Jalis, Faculty of Modern Languages and Communication, Universiti \\ Putra Malaysia, 43400 UPM Serdang, Selangor, Malaysia. E-mail: farhana.mjalis@gmail.com
}

Received: January 29, 2019

Accepted: March 13, 2019 Online Published: March 29, 2019

doi:10.5539/ass.v15n4p49

URL: https://doi.org/10.5539/ass.v15n4p49

\begin{abstract}
This study investigates similarities and differences in Malay and German refusal speech acts realised by their respective mother tongue languages, which are the Malay and German languages. This study analysed situations in which refusal could occur and examined the refusal strategies and corresponding linguistic forms used by the two groups when refusing requests made by higher, equal, and lower relationship status interlocutors. A Discourse Completion Test (DCT) was utilised to obtain data on the types and content of refusal strategies. The data gathered from the DCT was analysed and coded according to a combined taxonomy of refusal strategies proposed by Beebe et al. (1990) and Al-Issa (2003). The findings will provide future insights on the cross-cultural complexity of refusal interaction patterns used by both Malay and German speakers in order to understand and also avoid creating stereotypes of foreign culture. In addition, speakers may also adopt socially appropriate strategies for future situations that might be encountered in order to engender successful communication when dealing with refusals. The results are then discussed from the universality and cultural-specificity perspectives.
\end{abstract}

Keywords: cross-cultural, native speaker, pragmatics, refusal, request, speech act

\section{Introduction}

Language is the basis of all communication. According to Grein (2007), successful communication can only be achieved when both parties grasp the meaning of each utterance. Oftentimes, the meaning of an utterance, however, cannot be interpreted by merely understanding the spoken words or the sentence as a whole. In order to grasp the meaning of an utterance, the listener also has to analyse the situation in which the utterance is being made, the social distance between the interlocutors, the prior utterances, nonverbal aspects, the cognitive skills of the interlocutors, and their cultural background. The fundamental category of language usage is the speech act (Searle, 1969). In order to achieve communicative goals, speakers often employ a variety of speech acts (Tank, 2003). Speakers are not only simply saying something; they are also embedding actions into their speech act utterances. According to Olshtain and Blum-Kulka (1985), an empirical study on speech acts may provide a better understanding of how human communication is achieved through the use of linguistics behaviour. In addition, by conducting this empirical study, similarities and differences in interaction can be identified among different languages and cultures under similar situations. As a matter of fact, the realisation of a speech act is influenced by the social, cultural norms, and beliefs within the communities itself (Meier, 1995, 1997; Richard \& Schmidt, 1983).

Refusal is part of a speech act that includes the notion of reluctance, or unwillingness to decline or to accept. In addition, refusal is also an act that involves a negative response towards a given offer, request, invitation or suggestion (Sattar et al., 2011, p. 70). The speech act of refusal represents a linguistics challenge in any conversation since it expresses a discrepancy between the intentions of both requester and refuser. The ability to refuse is not easy, as often times people are reluctant to say "no" straight away. Beebe et al. (1990), in addition, acknowledge that refusal is subtle and hidden in nature and therefore is not easy to execute even if the communication took place between native speakers.

Hei (2009) stated that many people, including Malaysians, are prone to facing pressure when refusing due to the fact that they prefer to avoid confrontations rather than deal with matters directly. This is because Malaysians are 
a collective society and do not wish to embarrass others through refusal or rejection, as saying 'no' can be regarded as an offense. Hei (2009) added that such offence may be taken not just at a personal level, but also could extend to other family members as well. Although many Malaysians would prefer to be more direct when refusing, they, nevertheless, still face a hard time overcoming their cultural conditioning and upbringing. Hei (2009) concluded that, oftentimes many Malaysians tend to be indirect and often apply hedges when turning down a request.

In general, refusals are a rather complex type of speech act because it requires not only a high level of pragmatic competence, long sequences of negotiations, and cooperative achievements, but also call for face-saving manoeuvres to accommodate the noncompliant nature of the act (Gass \& Houck, 1999, p. 2; Fèlix-Brasdefer, 2006, p. 2160). Refusals are also considered to be face-threatening acts (Brown and Levinson, 1987) and belong to the commissive category due to the commitment of the refuser to (not) perform an action (Searle, 1977). Refusals function as a response to an initiating act and are considered a speech act by which a speaker "[fails]" to engage in an action proposed by the interlocutor (Chen, Ye, \& Zhang, 1995, p. 121). This study therefore focuses on the cross-cultural pragmatic speech act of refusal towards a request between Malay and German native speakers.

\section{Previous Literature on the Speech Act of Refusal}

Refusal is an act involving a negative response towards a given offer, request, invitation or suggestion (Sattar et al., 2011, p. 70). Searle \& Vanderveken (1985, p. 195) define refusal as the negative counterparts of acceptance, whereas 'consenting' correlates to rejection and refusals. Refusal may appear in all languages of the world, but do all languages refuse in the same manner? According to Beebe et al. (1990), despite the existence of the speech act, refusal is universal-it exists in all languages but the frequency of use, language context, and linguistics forms that are used vary across cultures.

According to Rubin (1983), a speech act reflects basic cultural values that may be specific to certain groups of speakers. Rubin (1983) also pointed out that the speech act is controlled by social norms and is contextual. It therefore acts as the framework to its implementation. Minimal knowledge related to cross-cultural speech acts and insensitivity to the form can result in intercultural and inter-ethnic aspects being affected. In various cultures, the manner of saying 'no' is probably more significant than the answer itself. The speaker must know when to use the appropriate form and its function. High levels of semantic competence are needed in order to avoid unpleasant feelings between speakers and to maintain good intercultural relationships. Such skills are very important since the "inability to say no has led to many non-native speakers offending their interlocutors" (Ramos, 1991). Therefore, sending and receiving a message with a 'no' in it is a task that requires special strategy or skill.

There has been an ample study done on inter-language/cross-cultural pragmatics within the various frameworks of speech acts. These studies focused on several other issues such as the production, perception, and pragmatic developments among native speakers and L2 learners during the realisation of various speech acts. Among the previous refusal studies are compliments (Wieland, 1995), complaints (Olshtain \& Weinbach, 1993), apologies (Intachchakra, 2004), requests (Kasanga, 2006; Hill, Ide, Ikuta, Kawasake \& Ogino, 1986) and requests and apologies (Achiba, 2003; Marquez-Reiter, 2000; Blum-Kulka \& Olshtain, 1986). A decent amount of studies has been made on cross-cultural refusals (Nikmehr \& Jaherdi, 2014; Sattar \& Farnia, 2014; Abarghoui, 2012; Al-shboul, Marlyna Maros, \& Mohamad Subakir, 2012; Sattar, Salasiah Che Lah, \& Raja Rozina, 2011; Khatani, 2008; Chen, 1996; Ramos, 1991). These studies focused on politeness strategies, speech act patterns produced by speakers, pragmatic transfers, language manifestations, socio-pragmatic competence, and more.

A decent amount of studies focusing on the study of refusal speech act in the Malay and German languages has been found throughout recent years. In Malaysia, several similar studies have been carried out. In the Malay culture, it is difficult to reject someone or something simply by saying 'no', especially to people or guests with higher social ranking. Therefore, Malaysians often use vague and indirect utterances as a strategy to be polite and to preserve one's dignity or to 'save face' (Mohd Ali, 1995; Sattar et al., 2011; Kathir, 2015).

Ismail (2017) concluded in her study that Malay respondents use more indirect refusal strategies when making refusals. She also found that when a respondent makes a direct refusal, more strategies would follow afterwards. This phenomenon happens because of the respondent's intention to mitigate any threat to the dignity of the interlocutor as well as to save his or her own face. It is also important for Malaysians to focus on the hearer's feeling when making the refusal. Ab Rahman (2017) in her study shows that the Malay society, up to the present time, still practices politeness through indirect speech in their daily communication, especially when making refusals. It is believed that this strategy is taken to preserve the speaker's dignity when refusing. In addition, 
religious terms also affect how Malays execute their refusals.

For Germans, on the other hand, Siebold \& Busch (2015) made a contrastive study on the culture-specific realisation of different types of refusals between German and Spanish people. Siebold \& Busch (2015) is of the opinion that Germans manifest communicative patterns and 'facework' strategic characteristics more than the "Western individual-orientation" in their linguistic realisation of refusal. This includes a high tendency to use direct refusal, a lack of affinity in their explanations, and the need for pragmatic clarity that delivers the refusal as the final outcome. Johnson (2013) did a study on the pragmatics of expressing refusal among Germans and Americans. The study found that, overall, there are many similarities between the two groups, and the differences were not that significant. However, there was a difference in the frequency and type of reported refusal. The greatest difference between the two groups was that the Americans preferred to use more alternative statements, whereas the German speakers preferred statements of reason when making indirect refusals.

Generally speaking, how to say "no" is more important than the answer itself. Refusal exists in all languages, but despite its universal nature, the frequency of use and the context and the linguistic forms that are used vary across cultures (Beebe et al., 1990). Hence, what is considered appropriate refusal behaviour may vary across cultures and misinterpretations are therefore likely to occur, as speakers rely on their "deeply held native values" in carrying out complicated and face-threatening speech acts such as refusals (Beebe et al., 1990, p. 68). Therefore, in order to refuse in a culturally appropriate way, an appropriate understanding and a certain amount of culture-specific knowledge is required. Altogether, the speech act of refusal can be described as a universal phenomenon, but the manner in which this speech act is understood may vary across cultures.

However, up until now, there has been no empirical study that has practically compared Malay and German refusal manners within the cross-cultural framework of their native languages. Thus, this study attempts to fill the gap in the field of cross-cultural pragmatics approach by investigating the strategies used by both languages-Malay and German - in implementing the speech act of refusal.

\section{Significance of Study}

The present study is significant in that it contrasts the pragmatic strategies of two different cultures, which are the Malaysian and German cultures - a language pair that has not gained much attention in the cross-cultural field. This current study is also beneficial, as it increases the volume of present studies done on cross-cultural pragmatics by providing related information on refusal patterns of Malay Native Speakers (MNS) and German Native Speakers (GNS). This work will also contribute insights into the values or beliefs, which govern the preference for Malay and German refusal strategies. Hence, the findings of this study will further contribute to the present understanding and knowledge on the refusal strategies of native speakers. The finding can also be used to gain pragmatics awareness for future and current learners on how people of different cultures behave and speak and therefore assist them to become familiar with a range of linguistics devices and practices in the target language, particularly the Malay and German languages.

\section{Methodology}

The present study adopts a qualitative research design. The data for this study were derived from open-end role-plays enacted by Malaysians in a Malay-language-oriented situation and German in a German-language-oriented situation. The situations for both languages are similar and predetermined. The refusal interactions were transcribed, coded, and analysed. The outcome of the data analysis aims to determine both similarities and differences in the choices of refusal strategies made by the two groups in refusing various power distance relationship status requests in formal and informal situations.

\section{Sample}

A total of 16 Malay Native Speakers (MNS) and German Native Speakers (GNS) participated in this pilot study. The native Malay speakers are employees from two local Malaysian Universities, whereas the native German speakers are employees, who have experience working in Malaysia. All participants are between 20 and 60 years old. The German participants were selectively chosen, as there are not many Germans working in one particular institution. Therefore, selected German native speakers were approached and invited to participate in this study.

\section{Instrument}

The study utilised an open-end role-play Discourse Completion Test (henceforth termed DCT) questionnaire. The written questionnaire consists of two parts. The first part is the Demographic survey, where questions such as personal background, language background, and academic qualification are asked. To ensure balance data is achieved between the two groups, an equal level of age group, profession, and education level was chosen for this particular study. 


\section{Discourse Completion Test}

A modified version of DCT developed by Beebe et al. (1990) was used. DCT is one of the most prominent instruments for data collection involving refusal speech acts. For this particular study, two sets of DCTs are prepared in two languages, namely the Malay and German languages. Each participant will receive one set of DCT questionnaires in their respective mother tongue language. Each DCT adapts a total of 6 open-end role-play request stimulus scenarios with 3 formal power distance relationships (higher, equal, and lower towards the interlocutor) and 3 informal relationships. Each participant is asked to refuse the given situation and to write his/her actual response if they had actually been in that situation.

\section{Data Analysis Method}

Data were analysed using a combined refusal taxonomy developed by Beebe et al. (1990) and Al-Issa (2003). The refusal interactions were transcribed, coded, and later analysed. The analysis examines the strategic preferences that both groups make. In addition, similarities and differences between the groups when encountering various power distance relationship requests in formal and informal settings were also examined.

\section{Coding Schema}

A coding schema (refer to Appendices) was used based on the original combination theoretical framework of Beebe et al. (1990) and Al-Issa (2003). After the data was coded, the schema was revised according to the adapted theoretical framework of this study. Due to the absence of some strategies, some refusal strategies that were not used were omitted from the data presented, but the data remains unchanged for the rest of the refusal strategies exhibited in this study.

\section{Results and Discussion}

The findings for the types and contents of refusal strategies made by the two groups, MNS and GNS, are presented according to three main categories i.e. direct, indirect, and adjuncts to refusal strategies. Overall, both the Malay and German groups produced a total of 440 strategies; the Malay respondents produced a total of 199 refusal strategies in all 6 situations, whereas the German respondents produced a total of 241 refusal strategies.

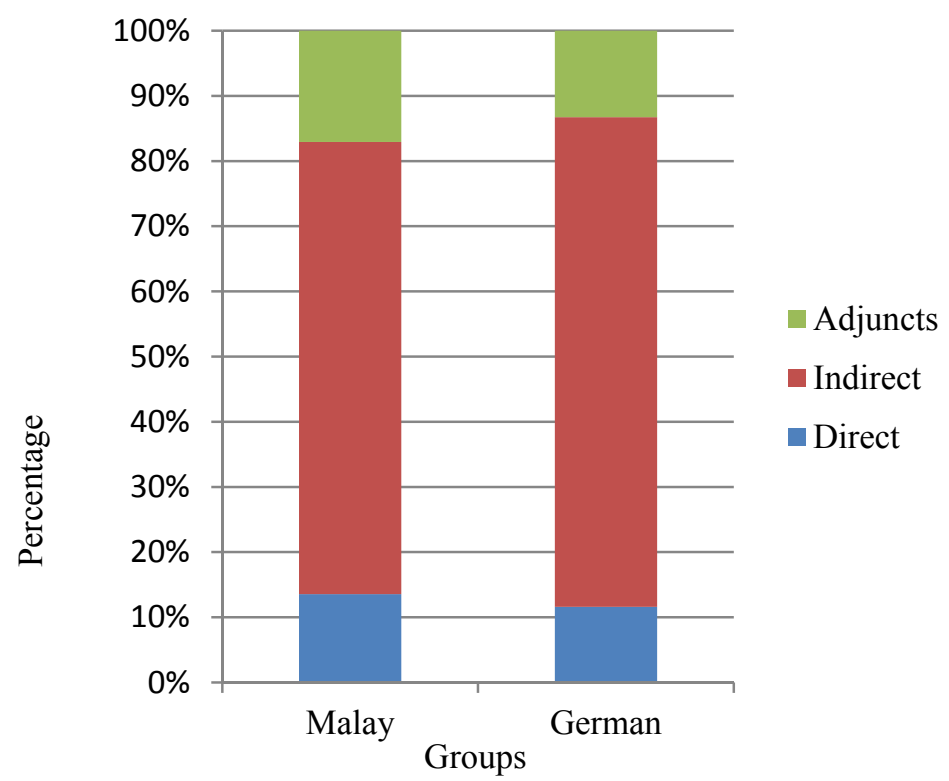

Figure 1. MNS vs. GNS refusal strategies to requests

In Figure 1, the percentage of direct refusals among MNS respondents (13.57\%) is slightly higher compared to the GNS respondents (11.62\%). In contrast, it has been found that the MNS respondents used a lower percentage of indirect refusal strategies $(69.35 \%)$ compared to the GNS respondents $(75.10 \%)$. This percentage suggests that the GNS respondents used more indirect strategies to refuse a request compared to the MNS respondents. The MNS respondents used a higher percentage of strategies involving adjuncts to refusal (17.08\%) compared to the GNS respondents, who used $13.28 \%$ of their overall refusal strategies for a request.

In Situation 1 (request to stay late), the respondent is asked by his/her head of department (formal - higher relationship towards the respondent) to stay late after office hours to finish some work. The findings revealed 
that the MNS respondents used more strategies compared to the GNS respondents (40 versus 28). The strategies used most by both groups are the "Excuses, reasons, explanations" strategy, and since most of the respondents are adults, family reasons were often used as well as a refusal strategy for the situation. However, the frequency of use of these refusal strategies was higher among the Malay respondents (11 times) compared to the German respondents (9 times). The MNS respondents used the "Statement of regret" strategy (8 times) more than that of the GNS respondents (5 times). From the data, almost all Malay respondents initiated their refusal strategies with a "Statement of regret" to show their respect towards a higher relationship power distance interlocutor and so as not to offend the interlocutor. Both groups used the same number of direct strategies to refuse a request made by equal relationship power distance interlocutors.

In Situation 2 (request to borrow a car), the respondent is asked by his/her colleague (formal - equal relationship towards the respondent) to borrow his/her car for the weekend. The findings revealed that the GNS respondents used more overall strategies compared to the MNS respondents (37 versus 27). The MNS respondents used the "Statements of regret" strategy the most ( 7 times) compared to the GNS respondents (4 times). In contrast, the GNS respondents used "Excuse, reason, explanation" the most (10 times) in Situation 2 compared to the MNS respondents, who used it 4 times only. Both groups used direct strategies the same number of times to refuse a request made by equal relationship power distance interlocutors.

In Situation 3 (request to increase salary), the respondent is asked by his/her employee (formal - lower relationship towards the respondent) to increase their monthly salary. The findings revealed that overall the GNS respondents used more strategies to refuse the request made by a lower relationship power distance interlocutor. The GNS respondents used 19.9\% of this strategy (a frequency of 48 times) compared to the MNS respondents, who used $18.6 \%$ of this strategy (a frequency of 37 times). Among the strategies, the Malay respondents used the "Conditional acceptance" strategy the most (a frequency of 6 times) compared to the German respondents (a frequency of 3 times). In contrast, the German respondents used the "Excuse, reason, explanation" strategy the most (9 times), compared to the Malay respondents (5 times). Interestingly, the GNS respondents resorted to direct strategies ( 7 times) more than the MNS respondents (5 times). This finding supports the work of Siebold $\&$ Busch (2015), in that Germans use direct strategies to clarify situations with the interlocutor.

In Situation 4 (request to accompany to a hospital), the respondent is asked by his/her grandmother (informal higher relationship towards the respondent) to accompany her to a hospital. Overall, the GNS respondents used more strategies compared to the MNS respondents (53 times versus 40 times). The findings revealed that both groups used the strategy "Excuse, reason, explanation" equally with a frequency of 10 times as a strategy to refuse the request of a higher informal relationship power distance interlocutor. Interestingly, the GNS respondents used the strategy "Threat or statement of negative consequences to the requester" more than the MNS respondents. As mentioned by Siebold \& Busch (2015), Germans feel the need to clarify their situation, and in this case, most of the cases related to this particular strategy involve the respondents attempting to let the grandmother (requester) know that there are negative consequences to the request being made. It may be assumed that the grandmother does not realise the negative consequences that may follow and therefore there is a need for the refuser to clarify. The GNS respondents also used more direct strategies compared to the MNS respondents (4 times versus 3 times). Another interesting finding is that the MNS respondents used the strategy "Define relation", a total of 8 times compared to the GNS respondents that used this strategy 6 times. In addition to the strategy above, between the requester and refuser, define relation was also used as a pronoun and therefore the frequency of its use was increased.

In Situation 5 (request to borrow a suit/dress), the respondent was asked by his/her cousin (informal - equal relationship towards the respondent) to borrow a suit/dress for an event. In the overall comparison, the GNS respondents used more strategies compared to the MNS respondents (38 times versus 27 times). The MNS respondents used direct strategies the most ( 7 times compared to 4 times). Interestingly, for this situation, the Malay respondents used the direct strategy "No" more than the German respondents. Due to the equality of power distance relationship and it being informal, the situation made the refuser feel less pressured to refuse the request. The data indeed proves this fact, where the overall frequency of refusal strategies is much less compared to other informal situations. In addition, the MNS respondents used the strategy of "Sarcasm" twice, whereas the GNS respondents did not use this strategy at all. In situation 5, it is found that the German respondents used the strategy "Excuse, reason, explanation" the most (9 times compared to the MNS respondents' frequency of 6 times).

The final situation is Situation 6. In Situation 6 (request to loan an amount of money), the respondent was asked by his/her niece (informal - lower relationship towards the respondent) to loan her money to pay tuition fees. In the overall comparison, the GNS respondents (frequency of 37 times) used more strategies to refuse a request 
from a lower relationship interlocutor compared to the MNS respondents (frequency of 28 times). The MNS respondents used the direct strategy of "Negative willingness/ability" the most with a frequency of 6 times. This is a slightly lower frequency compared to the GNS respondents, who used this strategy 7 times. In addition, the Malay respondents also used the informal "Excuse, reason, explanation" strategy as their second most preferable strategy for this situation. In contrast to the German respondents, the MNS respondents used the indirect strategy of "Statement of regret" and "Excuse, reason, explanation" the most, and with equal frequency. It is interesting to observe that the GNS respondents used this strategy more when dealing with a lower and informal relationship interlocutor. Although the direct strategy was used more, this is due to the intention of the refuser to clarify and amend the situation with a statement of regret to ensure mutual understanding is achieved.

Table 1. Frequency use of each refusal strategy for both groups in all six situations.

\begin{tabular}{|c|c|c|c|c|c|c|c|c|c|c|c|c|}
\hline \multirow{2}{*}{ Strategies } & \multicolumn{2}{|c|}{$\mathrm{S} 1$} & \multicolumn{2}{|c|}{ S2 } & \multicolumn{2}{|c|}{ S3 } & \multicolumn{2}{|c|}{$\mathrm{S} 4$} & \multicolumn{2}{|c|}{ S5 } & \multicolumn{2}{|c|}{ S6 } \\
\hline & $\mathrm{M}$ & G & $\mathrm{M}$ & $\mathrm{G}$ & $\mathrm{M}$ & $\mathrm{G}$ & $\mathrm{M}$ & $\mathrm{G}$ & $\mathrm{M}$ & $\mathrm{G}$ & $\mathrm{M}$ & $\mathrm{G}$ \\
\hline No & 0 & 0 & 0 & 1 & 0 & 0 & 0 & 0 & 4 & 1 & 0 & 0 \\
\hline Negative willingness/ability & 2 & 2 & 4 & 3 & 5 & 7 & 3 & 4 & 3 & 3 & 6 & 7 \\
\hline Statement of regret & 8 & 5 & 7 & 4 & 2 & 2 & 4 & 0 & 4 & 1 & 2 & 8 \\
\hline Wish & 0 & 0 & 0 & 0 & 1 & 1 & 0 & 0 & 0 & 0 & 0 & 0 \\
\hline Excuse, reason, explanation & 11 & 9 & 4 & 10 & 5 & 9 & 10 & 10 & 6 & 9 & 5 & 8 \\
\hline I can do $X$ instead of $Y$ & 0 & 0 & 0 & 0 & 0 & 0 & 0 & 2 & 0 & 0 & 0 & 0 \\
\hline Why don't you do X instead of $Y$ & 0 & 0 & 0 & 1 & 0 & 0 & 4 & 1 & 0 & 4 & 3 & 3 \\
\hline Future or past acceptance & 2 & 1 & 0 & 0 & 0 & 1 & 1 & 3 & 0 & 3 & 0 & 1 \\
\hline Conditional acceptance & 1 & 1 & 0 & 1 & 6 & 3 & 2 & 0 & 0 & 6 & 2 & 1 \\
\hline Promise for future acceptance & 5 & 5 & 0 & 1 & 3 & 6 & 0 & 3 & 0 & 1 & 0 & 1 \\
\hline Statement of principle & 1 & 1 & 0 & 2 & 0 & 0 & 0 & 0 & 0 & 0 & 0 & 1 \\
\hline $\begin{array}{l}\text { Threat or statement of negative consequence to the } \\
\text { requester }\end{array}$ & 0 & 0 & 0 & 3 & 0 & 0 & 3 & 8 & 0 & 1 & 0 & 0 \\
\hline Guilt trip & 0 & 0 & 0 & 0 & 3 & 6 & 0 & 0 & 0 & 0 & 0 & 0 \\
\hline Criticise the request/requester, etc. & 0 & 0 & 0 & 1 & 1 & 0 & 0 & 2 & 1 & 0 & 2 & 0 \\
\hline $\begin{array}{l}\text { Request for help, empathy, and assistance by dropping or } \\
\text { holding the situation. }\end{array}$ & 0 & 0 & 0 & 0 & 1 & 0 & 0 & 3 & 0 & 1 & 0 & 1 \\
\hline Reprimand & 0 & 0 & 0 & 0 & 1 & 1 & 0 & 0 & 1 & 1 & 1 & 1 \\
\hline Sarcasm & 0 & 1 & 0 & 0 & 0 & 0 & 0 & 0 & 2 & 0 & 1 & 0 \\
\hline Acceptance that functions as a refusal & 0 & 0 & 0 & 0 & 0 & 0 & 0 & 0 & 0 & 1 & 2 & 0 \\
\hline Avoidance & 0 & 0 & 0 & 0 & 0 & 0 & 0 & 0 & 1 & 0 & 0 & 0 \\
\hline Hesitation & 1 & 0 & 0 & 0 & 0 & 0 & 0 & 0 & 0 & 0 & 0 & 0 \\
\hline Joke & 0 & 0 & 1 & 0 & 0 & 0 & 0 & 0 & 0 & 0 & 0 & 0 \\
\hline Repetition of part of request, etc. & 0 & 0 & 0 & 1 & 0 & 0 & 0 & 0 & 0 & 0 & 0 & 0 \\
\hline Postponement & 0 & 0 & 0 & 0 & 2 & 0 & 1 & 1 & 0 & 0 & 0 & 0 \\
\hline Hedging & 1 & 1 & 0 & 1 & 0 & 0 & 0 & 1 & 0 & 1 & 0 & 0 \\
\hline Request for information & 0 & 0 & 0 & 4 & 0 & 0 & 0 & 4 & 0 & 0 & 0 & 1 \\
\hline Return favour & 0 & 0 & 0 & 3 & 0 & 0 & 2 & 1 & 0 & 1 & 2 & 1 \\
\hline Statement of positive opinion/feeling or agreement & 0 & 0 & 0 & 0 & 0 & 1 & 0 & 0 & 0 & 0 & 0 & 0 \\
\hline Statement of empathy & 0 & 0 & 0 & 0 & 0 & 2 & 0 & 0 & 0 & 0 & 0 & 1 \\
\hline Pause fillers & 0 & 0 & 1 & 0 & 0 & 0 & 2 & 0 & 5 & 1 & 1 & 0 \\
\hline Gratitude/appreciation & 0 & 0 & 0 & 0 & 3 & 3 & 0 & 0 & 0 & 1 & 0 & 0 \\
\hline Removal of negativity & 1 & 1 & 0 & 1 & 4 & 5 & 0 & 4 & 0 & 2 & 0 & 0 \\
\hline Define relation & 7 & 1 & 1 & 0 & 0 & 1 & 8 & 6 & 0 & 0 & 1 & 0 \\
\hline Total & 40 & 28 & 27 & 37 & 37 & 48 & 40 & 53 & 27 & 38 & 28 & 37 \\
\hline
\end{tabular}


Finally, in relation to power distance, this study used formal and informal relationships as a variable to determine the data analysis. As mentioned in Table 2, it was found that the MNS respondents used a higher percentage of strategies when dealing with formal relationships (52.26\%) compared to informal relationships $(47.74 \%)$. This data shows that Malays use more strategies to refuse a request when faced with formal relationships. This data supports the statement made by Hei (2009), in that Malays is a collective society and are concerned about society's values and opinions. The higher percentage of refusal frequency suggests that Malay speakers tend to mitigate the situation using face-saving manoeuvres, which results in a higher-frequency strategy taking. In S1, it was found that Malays use more refusal strategies with a higher relationship interlocutor. This shows that the MNS respondents attempt to mitigate any negative intention in order to prevent the higher relationship interlocutor from feeling offended. In addition, the respondents (refuser) also offered alternatives as a way to amend the situation. German speakers, on the other hand, used more direct strategies and less refusal strategies in formal settings compared to Malay speakers. This data suggests that Germans believe that it is important to be clear when uttering a response to avoid any misunderstandings or ambiguities, as mentioned by Siebold \& Bush (2015).

Table 2. Percentage frequency of refusal strategies used between Malay and German native speakers in formal and informal settings

\begin{tabular}{ccccc}
\hline \multirow{2}{*}{ Strategy } & \multicolumn{2}{c}{ Formal } & \multicolumn{2}{c}{ Informal } \\
\cline { 2 - 5 } & $\mathrm{M}$ & $\mathrm{G}$ & $\mathrm{M}$ & $\mathrm{G}$ \\
\hline Direct & 11 & 13 & 16 & 15 \\
Indirect & 76 & 85 & 62 & 96 \\
Adjuncts & 17 & 15 & 17 & 17 \\
Total frequency & 104 & 113 & 95 & 128 \\
Percentage & $52.26 \%$ & $46.89 \%$ & $47.74 \%$ & $53.11 \%$ \\
\hline
\end{tabular}

M (Malay MNS) G (German GNS)

Interestingly, the German respondents used more strategies when faced with a higher relationship interlocutor in both formal and informal situations. In Situation 3 (S3), the Germans used refusal strategies 48 times (19.9\%) versus Malays, who used the strategies 37 times (18.6\%). In Situation 6 (S6), the Germans used the strategies 37 times (15.35\%) versus the Malays that used it 28 times (14.07\%). The German respondents showed respect towards lower power distance relationship interlocutors. The findings show that the GNS respondents used more strategies to refuse a request from a lower power distance relationship compared to other situations.

In informal settings, it was found that Malays used fewer strategies and were more direct with all levels of power distance relationship interlocutors compared to Germans. There is no doubt that the respondents felt more comfortable executing refusals, as they felt closer to the interlocutor and therefore deemed it okay to refuse. German speakers were found to make equal direct and indirect strategies in two out of three situations (S4 and S5). However, in S6, it was found that both the MNS and GNS respondents used similar strategies with $87.5 \%$ of direct refusal strategies made by both groups. However, the GNS respondents differed in terms of frequency count (Germans used this strategy 37 times while the Malays used it 28 times).

\section{Conclusion}

Overall, this study has proven that GNS prefer slightly more direct strategies compared to MNS but this differed according to the situation being formal or not. In terms of frequency count, GNS used much more strategies compared to MNS. German speakers used more strategies in their overall response (Germans used 241 strategies vs. Malays that used 199 strategies). The most-used strategy was "Excuse, reason, explanation". Often times, German speakers explained or provided information to the interlocutor on why the refusal was being made. As an individualist society, they feel that it is healthy to speak their mind about something that is right. The indirect refusal strategy of "Excuse, reason, explanation" was the most preferred refusal strategy for both groups. However, the GNS respondents used this refusal strategy more than the MNS respondents-55 times $(22.82 \%)$ versus 41 times (20.6\%). The Malay respondents, however, tend to use statements of regret. In particular, they would apologise as part of their refusal strategy more frequently than Germans.

In formal settings, Malay respondents preferred to use more indirect strategies to refuse a request, whereas the German respondents used an equal number of strategies. From the three formal settings, the Malay respondents 
used the most number of strategies in S1 (formal, higher relationship status with refuser). This data proves that, as a collective society, Malay speakers tend to mitigate a refusal response and therefore use more strategies. MNS also prefer to use indirect strategies for this particular situation. For German speakers on the other hand, they prefer to use slightly more direct strategies but with lesser frequency. This shows that GNS use direct and lesser strategies in order to be clear and avoid ambiguity. The findings also support the German pragmatics behaviour, which aims to be clear when conveying a message to avoid ambiguity. Interestingly, for informal settings - S4 and S6 - the number of strategies used is equal for both MNS and GNS. Both groups prefer more direct refusal strategies towards their interlocutors' request; only differing in frequency count. GNS still used more strategies when refusing their interlocutor.

An interesting difference between the two groups of respondents is that the Malay respondents tend to use statements of regret in their refusal strategy more frequently than German native speakers. Malay speakers also commonly used religious terms in their refusal strategy. Malays often used the term 'In shaa Allah' (Arabic word meaning 'if God wills'), which they also use to execute refusals. In addition, it was also found that MNS used more strategies when addressing an interlocutor with a higher relationship status, whereas Germans used more strategies when addressing a lower relationship status interlocutor. This study however, was conducted on a small group of participants. If a larger amount of respondents were used, the analysis results for this study would be different.

The study concludes that the respondents from both groups use similar strategies to execute refusals, only differing in terms of frequency of use and trends. This study was conducted based on a cross-cultural pragmatics platform. It is hoped that the outcome of this study will increase awareness related to cultural differences in both the Malay and German culture and reduce cultural misunderstanding. Cultural orientation moulds a society, when society actually needs to be aware of different cultures instead of making allegations or creating stereotypes. Such awareness of cultural diversity of attitudes and language behaviour should be embraced and accepted and not be seen as something abhorrent or abnormal. Therefore, it is hoped that this study will add value, norms, and knowledge as well as give pointers on hidden language behaviours, which can potentially reduce misunderstanding and increase tolerance across cultures.

\section{Appendices}

\section{Appendix A: Classification of refusal by Beebe et al., (1990)}

\section{Direct refusal}

- Performative (e.g, "I refuse")

- Nonperformative

- "No"

- Negative willingness (e.g, "I can't"; “I won't"; "I don't think so")

\section{Indirect refusal}

- Statement of regret (e.g, "I'm sorry..."; "I feel terrible...")

- Wish (e.g, "I wish I could help you...")

- Excuse, reason, explanation (e.g, "My children will be home that night"; "I have a headache")

- Statement of alternative:

- I can do X instead of Y (e.g, "I rather..."; "I prefer...")

- Why don't you do X instead of Y (e.g, "Why don't you ask someone else”)

- Set condition for future or past acceptance (e.g, "If you had asked me earlier, I would have...")

- Promise for future acceptance (e.g, "I'll do it next time"; "I promise I'll..."; "Next time I'll ...")

- Statement of principle (e.g, "I never do business with friends")

- Statement of philosophy (e.g, "One can't be too careful”)

- Attempt to dissuade the interlocutor:

- Threat or statement of negative consequences to the requester (e.g, "I won't be any fun tonight")

- Guilt trip (e.g, "I can't make a living of people who just offer coffee") 
- Criticise request/requester, etc. (statement of negative feeling or opinion) ; insult/attack (e.g, "That's a terrible idea!"; "Who do you think you are?")

- Request for help, empathy and assistance by dropping or holding the request (e.g, )

- Let interlocutor off the hook (e.g, "Don't worry about it"; "That's okay"; "You don't have to")

- Self-defence (e.g, "I'm trying my best"; "I'm doing all I can do")

- Acceptance that functions as a refusal:

- Unspecific or indefinite reply

- Lack of enthusiasm

- Avoidance:

- Nonverbal

- Silence

- Hesitation

- Do nothing

- Physical departure

- Verbal

- Topic switch

- Joke

- Repetition of part of request, etc. (e.g, "Monday?")

- Postponement (e.g, "I'll think about it")

- Hedging (e.g, “Gee, I don't know”; “I’m not sure”)

\section{Adjuncts to refusal}

- Statement of positive opinion / feeling or agreement (e.g, "That's a good idea" ; "I'd love to")

- Statement of empathy (e.g, "I realise you are in a difficult situation")

- Pause fillers (e.g, "Uhh"; "Well”; "Oh”; "Uhm”)

- Gratitude / appreciation (e.g, "Thank you very much")

\section{Appendix B: Modified version of Beebe et al. (1990) in Al-Issa (2003:599)}

\section{Direct}

- Performative: (e.g., "I refuse)

- Explicit rejection (e.g. "hell no"; "no way")

- Nonperformative:

- "No"

- "Negative ability/willingness (e.g., "I can't”)

II Indirect

- Regret (e.g., "sorry..."; “excuse me...”; "forgive me...”)

- Wish (e.g., "I wish I could")

- Explanation/Excuse (e.g., "I have to study"; "I'm very busy")

- Alternative (e.g., “why don't you do X instead of Y?”; "I'd rather...”; “I'd prefer...”)

- Future or past acceptance (e.g., "Can we do it next week?", "If you asked me ten minutes ago...”)

- Statement of principle (e.g., "I don't borrow money from friends", "I don't ride with strangers")

- Negative consequence (e.g., "I'm afraid you can't read my notes")

- Insult/Attack/Threat (e.g., “who asked about your opinion?”; “If you don't get out of here, I'll call the police") 
- Criticize (e.g., "that's a bad idea", "you are lazy”)

- Let interlocutor off the hook (e.g., "Don't worry about it"; "That's okay"; "You don't have to")

- *Reprimand (e.g., "You should attend classes too", "You shouldn't wait till the last minute")

- *Sarcasm (e.g., "I forgot I'm your servant!”)

- *Conditional acceptance (e.g., "If I finish early, I'll help you")

- Hedging (e.g., "I don't know: I'm not sure")

- Postponement ("I'll think about it")

- *Request for information (e.g., "Why do you think I should take it?")

- *Request for understanding (e.g., "Please understand my situation")

- *Return favour (e.g., "I'll pay for you and me")

- Positive opinion/feeling/agreement (e.g., "That's a good idea but...”)

- Pause fillers (e.g., "Uhh”; "Well...”; “Oh...”)

- Gratitude (e.g., "Thank you very much", "I appreciate it")

- *Removal of negativity (e.g., "You are a nice person but...”)

- *Define relation (e.g., "Okay my dear Professor but...”)

*Indicates additional categories Al-Issa (2003) made to Beebe et al. (1990) based on the corpus of the current study.

\section{References}

Ab Rahman, N. J., \& Yusof, M. (2017). Strategi Berkomunikasi Generadi Muda Melayu: Analisis Lakuan Bahsa Penolakkan. Jurnal Melayu (2017).

Al-Issa, A. S. (2003). Sociopragmatic transfer in the performance of refusals by Jordanian EFL learners: Evidence and motivating factors (Ph.D Thesis). Indiana University of Pennsylvania, Indiana, Pennsylvania.

Beckers, A. M. (2003). How to say no without saying No: A refusal study of the refusal strategies of Americans and German (PhD Thesis). The University of Mississippi, Mississippi.

Beebe, L., Takahashi, T., \& Uliss-Weltz, R. (1990). Pragmatics Transfer in ESL Refusals. In C. S. Robin, \& S. A. Elaine (Eds.), Developing Communicative Competence in a Second Language (pp. 55-73). Newbury House Publishers, New York USA.

Blum-Kulka, S. (1982). Learning to say what you mean in a second language: A study of the speech act performance of learners of Hebrew as a second language. Applied Linguistics, 3, 29-59. https://doi.org/10.1093/applin/3.1.29

Blum-Kulka, S., \& Olshtain, E. (1984). Request and apologies: A cross-cultural study of speech act realization patterns CCSARP. Applied linguistics, 5, 196. https://doi.org/10.1093/applin/5.3.196

Cho, Y. (2007). Refusals and Politeness in directive action games: Cultural differences between Korean and German. Dialogue and Culture, 1, 191. John Benjamin. https://doi.org/10.1075/ds.1.14cho

Grein, M. (2007). The Speech Act of Refusals within the Minimal Action Game: A comparative study of German and Japanese. Dialogue and Culture, 1, 191. John Benjamin. https://doi.org/10.1075/ds.1.08gre

Hei, K. C. (2009). Moves in Refusal: How Malaysian says 'No'. China Media Research, 5(3), 31-44.

Ismail, R. (2017). The Difference of Speech Act of Refusal Strategies between the Malays and Spanish: Cross-cultural Studies. The Social Sciences, 12(8), 1334-1343.

Jamilah Mohd Ali. (2000). Verbal communication: A study of Malaysian Speaker. University of Malaya Press.

Johnson, A. (2014). The Pragmatics of Expressing Refusals in German and American English. Kwansei Gakuin University humanities review, 18, 105-125.

Kasper, G., \& Blum-Kulka, S. (Eds.) (1993). Interlanguage pragmatics. New York: Oxford University Press.

Kathir, R. (2015). Refusal Strategy: Patterns of Refusal Amongst Language Academicians at Public Universities At Malaysia. Journal of Education and Social Sciences, (1). 
Norma Saad. (2016). Refusal and linguistics politeness: A comparative study of Malay speakers and native speaker of English (Unpublished PhD thesis). Universiti Utara Malaysia.

Olshtain, E. (1983). Sociocultural competence and language transfer. A case of apology. In G. Kasper, \& S. Blum-Kulka (Eds.), Interlanguage pragmatics. New York: Oxford University Press.

Rubin, J. (1983). How to tell when someone is saying 'No'. In N. Wolfson, \& E. Judd (Eds.), Sociolinguistics and language acquisition. Massachusetts: Newbury House Publishing.

Sattar, H. Q. A., Lah, S. C., \& Suleiman, R. R. R. (2012). Refusal strategies in English by Malay university students. GEMA Online Journal of Language Studies, 11(3).

Searle, J. R. (1969). Speech acts: An essay in the philosophy of language. Cambridge: Cambridge University Press. https://doi.org/10.1017/CBO9781139173438

Zhu, J., \& Bao, Y. (2010). The Pragmatic comparison of Chinese and western "politeness" in cross-cultural". Journal of language Teaching and Research, 1(6), 848-851. https://doi.org/10.4304/jltr.1.6.848-851

\section{Copyrights}

Copyright for this article is retained by the author(s), with first publication rights granted to the journal.

This is an open-access article distributed under the terms and conditions of the Creative Commons Attribution license (http://creativecommons.org/licenses/by/4.0/). 